\title{
PRELIMINARES DE LA GUERRA DE LOS DOS PEDROS EN EL REINO DE VALENCIA (1356)
}

\author{
María Rosa Muñoz Pomer
}

La financiación de la estructura político-administrativa de la Corona de Aragón se hace independientemente en cada uno de sus reinos. El mantenimiento se efectua en un doble plano: el municipal, cuyos gastos serán sufragados con la recaudación de los impuestos de la ciudad, emisión de censales y otros recursos a criterio del Consejo y los jurados; y las necesidades de la corona, a las que se contribuirá con lo percibido por los impuestos reales, siempre escasos, que harán necesario arbitrar otros medios, especialmente en los momentos conflictivos, momentos que no faltarán a lo largo del s. XIV. Estas medidas serán: los préstamos y colaboración solicitada a las ciudades, venta del patrimonio real, impuestos extraordinarios, donativos de la Cortes, etc. todos estos procedimientos, ensayados con anterioridad, se utilizarán asiduamente en este siglo, de tal forma que es en este período cuando se consagra el impuesto general votado en Cortes y que, andando el tiempo, dará lugar a la llamada Generalidad.

La debilidad del sistema financiero es reconocida por el mismo monarca: «Nós no som rey qui hajam tresor ni grans rendes, et ço 
que nós havem a metre en aquests affers, havem a trer de nostres gents, les quals en temps passat, en nostres guerres e en nostres affers, nos han molt ajudat" (1).

Uno de los acontecimientos que pondrá en funcionamiento los mecanismos financieros, antes mencionados, será el enfrentamiento entre Castilla y la Corona de Aragón conocido como «La guerra de los dos Pedros» (1356-1369).

La transcendencia y prolongación del conflicto hará necesario que de forma individual o simultánea vayan aplicándose los distintos resortes económicos. Las circunstancias establecerán su prioridad.

Las características de esta guerra, cuyas primeras acciones comienzan incluso antes de su declaración formal, hacen necesaria, en primer lugar y sobre todo en la zona fronteriza, la colaboración de las ciudades para hacer frente a la situación.

Las Cortes también aportarán su ayuda pero, en el caso de València, ésta será posterior, aunque no por ello menos importante. Los representantes del reino se reunirán con este fin en: 1358, 1360, 1362, 1364 y 1367 (2). Las primeras Cortes, pues, se convocan durante la tregua establecida a partir de mayo de 1357 .

El estudio del papel que desempeña la ciudad de València, a tra. vés de su órgano representativo: el Consejo, ha sido posible por la calidad de los fondos documentales que conserva su archivo municipal.

Fuente principal para este fin es Manual de Consells (3), en ella se registran todos los acuerdos tomados por su corporación. Hemos revisado, asimismo, Lletres Missives (4), y Claveria Comuna, Manuel D'Albarans (5). Hay que lamentar la carencia para estas fechas de Claveria Comuna. Llibres de Comptes. Esta serie recoge los ingresos y gastos del municipio y en ella quedaron reflejados, sin

(1) GUBERN, R., Epistolari de Pere III. Barcelona, 1955. p. 144-145. Carta escrita al infante Pedro el 24 de febrero de 1357.

(2) ROMEU ALFARO. S. , Catálogo de Cortes Valenciana hasta 1410. Anuario de Historia del Derecho español. t. 40; (1970), p. 593.

(3) En adelante se citara (M.C.) El M.C., A-13, abarca de 1356 a 1360.

(4) Citado (L.L. M.). El LL. M., g3-2, aunque consta en su encuadernación que comprende de 1349 a 1356 , su contenido finalizará en realidad en 1352.

(5) Citado (C.C.M.A.), es un registro de albaranes y sólo proporciona datos parciales aunque en algunos casos pueden ser indicativos. 
duda, las cifras globales y los conceptos de las inversiones hechas durante la guerra.

\section{ANTECEDENTES}

El hecho de que ambos estados, Castilla y la Corona de Aragón, se desenvolviesen dentro de la misma unidad peninsular y bajo la tradición goda de unidad política será la causa, según Abadal (6), de su enfrentamiento. La dualidad comenzada ya en el s. XII, época de expansión de ambas - Tudilen, 1151 - , finalizará con el tratado de Almazán - 1375 - . Los resultados de la guerra de los dos Pedros darán fin a las ilusiones expansivas del Ceremonioso.

Aunque con Jaime II parecía haberse llegado a una situación de equilibrio que se intenta consolidar con el matrimonio de Dña. Leonor, hija de Fernando IV, y el heredero aragonés, el enlace de Alfonso IV y la infanta castellana no responderá a las esperanzas puestas en él. Las donaciones, que ésta obtendrá del rey en favor de sus hijos y en detrimento del primogénito, serán la causa del enfrentamiento entre Pedro IV y Alfonso XI, hermano de aquella, que asume su causa a la muerte de su esposo ante la actitud del heredero.

El peligro benimerín, no obstante, decide su concordia y colaboración en la campaña del estrecho (7).

El acceso al trono castellano de Pedro I no supone ruptura de la paz, aunque como señala Zurita: «Estuvieron el rey de Castilla desde que sucedió en aquel reino y el rey de Aragón en gran recelo de rompimiento» (8), la causa, según el mismo señala, se enlaza con los hechos antes mencionados, la relación de ambos monarcas con respecto a los hermanastros del contrario.

El pacto de Tarazona - 4 de octubre de 1352 - zanja las cuestiones en torno a Dña. Leonor y sus hijos evitando por el momento su enfrentamiento, enfrentamiento nada fácil en esos años: el cas-

(6) ABADAL, R. d', Pedro el Ceremonioso y la decadencia política de Cataluña. Prólogo t. XIV de Historia de España, dirigida por R. Menéndez Pidal, p. 131 y ss.

(7) MUÑOZ POMER, M $^{\mathrm{a}} \mathrm{R}$,, Las Cortes de 1339 paso previo en la alianza peninsular contra los Benimerines. Homenaje al Dr. Peset (en prensa).

(8) ZURITA, J. (1562), Anales de Aragón, ed preparada por CANELLAS, A. Zaragoza. 1977, t. 4 p. 254. 
tellano andaba ocupado en la represión de la nobleza y Pedro IV en la campaña de Cerdeña.

La paz, sin embargo, no sería duradera. Pedro I, tras someter a la nobleza en 1355, dedica su atención a la política exterior, que dará como resultado lo que Zurita ha calificado como: "Guerra furiosa entre los reyes de Aragón y Castilla» (9), y en la cual el Ceremonioso: "Estuvo en peligro de perder el reino y vio gran parte dél en poder de su enemigo" (10). Como señala Suárez Fernández: «Desde el primer momento la guerra entre Castilla y Aragón se mostró muy diferente de las acostumbradas rivalidades fronterizas; iba a ser la batalla decisiva por la hegemonía peninsular" (11).

Al detonante que hizo estallar la guerra, según las crónicas de ambos reyes, Zurita añade algunas quejas en las que estaban implicados como otras veces los hermanastros y bastardos, él mismo recoge, que «Aunque el rey de Castilla fue el promovedor de la guerra y ligeramente admitió la ocasión della, estaban ya muchos días antes los ánimos destos príncipes muy indignados y con grande sentimiento y queja el uno del otro" (12).

La concordia del Castellano con los hermanastros del Aragonés, los infantes Fernando y Juan, que le ofrecieron, entre otros, los castillos de Orihuela y Alacant, es una de las querellas que alega el Ceremonioso (13). Las de Pedro I serán presentadas por un embajador tras el incidente que causa la ruptura (14).

La política seguida por el rey de Castilla con respecto a la nobleza justifica, por un lado, el intento de concordia del infante Juan con su hermanastro, y por otro, la salida de sus nobles hacia Francia y Aragón. El exilio de nobles castellanos favorece las gestiones diplomáticas de Pedro IV.

El incidente que originó el enfrentamiento fue la actitud de Francesc de Perellós, súbdito aragonés, en su camino hacia el canal de la Mancha como aliado de los franceses en su enfrentamiento a

(9) Idem, p. 289.

(10) Ibidem.

(11) SUAREZ FERNANDEZ, L., Castilla 1350-1406 en t. XIV de la Historia de España dirigida por R. Menendez Pidal, p. 47.

(12) ZURITA. J., Op. Cit., p. 290.

(13) Gubern, R., Op. Cit., p. 145-146.

(14) ZURITA, J., Op. Cit., p. 295-296. 
Inglaterra, en la denominada: "Guerra de los cien años», al tomar dos barcos de mercaderes en contra de la voluntad del castellano.

Pedro I, a fin de hacerle desistir de su empeño, le amenaza con prender y embargar a los mercaderes catalanes afincados en Sevilla; ante la actitud de Perellós, el rey dio orden de ejecutar la amenaza.

\section{PRELIMINARES DE LA GUERRA}

El ultimátum de Pedro I no llegará al Ceremonioso hasta el 4 de septiembre de 1356 (15); ello no impide que, con anterioridad a esta fecha, las zonas fronterizas sean hostigadas por los castellanos.

La preocupación por estos ataques y el interés por conocer la situación de los mercaderes que se encontraban en Sevilla mueven al Consejo municipal valenciano a enviar espías a Castilla con el fin de obtener información (16).

Las primeras noticias registradas en las actas del Consejo no procederán, sin embargo, de esta fuente.

Son el infante Ramón Berenguer, conde de Ampurias, y el gobernador general, García de Lóriz, miembros del Consejo real residente en Valencia, y sin duda por delegación, los que personados en su reunión del 31 de julio informan al Consejo:

"Que ells havien haüdes letres e noves que.l rey de Castella havia preses tots e sengles mercaders catalans, los quals havia trobats en la ciutat de Sibília; hoc encara en Múrçia eren stats preses tots e sengles mercaders catalans, los quals eren e mercadejaven en aquella, e totes les robes e coses e mercaderies de aquells scrites, emparades e secrestades. Et enaprés, havien entés, lo dit senyor infant e lo dit honrat governador, que.l dit rey de Castella havia armades nou galees e quatre naus, en les quals aquell personalment era pujat, e s'esforçava més armar-ne per dapneyar catalans e altres sotmeses del molt alt senyor nostre, lo rey d'Aragó.

Item, encara fon propossat, per lo dit senyor inffant e governa-

(15) Idem, p. 298

(16) A finales de julio cobran su salario, 100 sueldos cada uno, Pere de Torreblanca, portero del rey dos castellanos que habían ido a Sevilla a obtener información sobre los merca. deres (C.C.M.A., J-2, f. 3, 3v). 
dor desús dit, que.l dit rey de Castella e los alts infants don Ferrando, marqués de Tortosa, e don Johan, frares del dit senyor nostre, lo rey d'Aragó, s'esforçaven e fahien tot son poder per entrar en los regnes d'Aragó e de València en gran da e perjudiçi del dit senyor rey e dels dits regnes" (17).

Comunicadas estas nuevas, el gobernador manda a los jurados y al Consejo: "Que sobre les dites coses fesen e ordenasen tals e tant bones provissions, que fossen a honor del dit senyor rey e a profit e utilitat de la dita ciutat e regne de aquella" (18).

El Consejo, ante la gravedad y urgencia de los hechos, aprueba por unanimidad que el infante y el gobernador junto a los jurados:

«Triasen e helegisen, axí per part dels cavallers ho generosos com dels ciutadans de la dita ciutat, alcunes bones persones" (19); y que todos ellos decidan y ordenen lo necesario en relación a estos hechos. Rapidamente se procede a la elección de una delegación y esa misma tarde se acuerdan las primeras medidas orientadas al abastecimiento y la defensa.

El abastecimiento quedará cubierto con dos tipos de soluciones:

$1^{\circ} \mathrm{El}$ aprovisionamiento de los puntos estratégicos (20). El gobernador se ocupará de Valencia dando las órdenes oportunas; dos representantes de esta comisión, del resto de villas y castillos, especialmente los situados en la línea Bunyol-Castielfabib.

$2^{\circ}$ Por medio de la notificación de estos hechos a fin de que cada lugar proceda a la custodia y defensa de sus ganados y otros bienes.

La defensa exigirá mayores disposiciones:

$1^{\circ}$ Dedican su atención a la frontera sur. El gobernador debe partir hacia Xàtiva, el baile a la Villa Joiosa para encomendar su castillo a alguien de absoluta confianza.

(17) M.C., A-13, mano 1, f. 12-12v.

(18) Idem, f. $12 \mathrm{v}$

(19) Idem, f. 12v. Esta comisión quedará formada por el infante el gobernador, los jurados y los siguientes miembros del Consejo: Berenguer d'Abellà, Galceran de Tous, Bernat Fabra, Joan de Pertusa, Francesc de Vilarasa, Pasqual Maçana, Giner Rabaça, Ramon de Vilanova, Vicent Dezgraus, Jaume de Claramunt, Bertomeu Mulnar, Miquel Pellicer, Pedrolo Gil, Guillem Abelló, Miquel de Palomar, Francesc Marrades, Pere Malet, Pere Fuser, Arnau de Valleriola, Andreu Caner, Jaume Delmas, Guillem d'Espígol, Lop de Piera, Romeu Soler, Jaume Guerau, Pere Rull, Mateu Ibanyes y Berenguer Tapioles.

(20) C.C.M.A., J-2, f. 15, recoge el salario de los que se ocuparon de aprovisionar de trigo la ciudad y otras fortalezas. (Idem, f. 19v.) lo que cobra el encargado de supervisar el trigo de que dispone el reino. 
$2^{\circ}$ Se procederá al recuento y organización de efectivos. Los jurados se ocuparán de contabilizar los jinetes y distribuir los infantes en decensas y centenas (21). En la ciudad de València delegarán estas función en dos miembros de cada parroquia (22).

$3^{\circ} \mathrm{El}$ gobernador se ocupará de establecer el código de señales y de su comunicación a todo el reino (23); además localizará los lugares más apropiados para situar el frente.

$4^{\circ}$ Dos de los jurados que forman la comisión se encargarán de organizar el espionaje (24).

$5^{\circ}$ Se prohibe la exportación de rocines, caballos y armas. El baile será el encargado de difundir la noticia y de alertar a los oficiales responsables en las fronteras.

$6^{\circ}$ Con respecto a los castellanos que habitan en la ciudad se dispone que no les sea encomendado el peaje y que se le retire si alguno lo está disfrutando. Ordenándose, al mismo tiempo, que si es necesario sean expulsados de la ciudad de Valencia e incluso del reino (25).

Las disposiciones, como puede observarse, abarcan todos los aspectos poniendo especial atención a las zonas de acceso al reino.

El 13 de agosto, y a causa de las informaciones que llegan de Castilla, el Consejo adopta nuevas medidas. Siguiendo el criterio ya establecido, decide el nombramiento de una comisión (26) que deberá hacerse cargo de la fortificación de la ciudad. Así mismo, acuer-

(21) Idem, f. 6, Joan de Bonfill organizó los de la contribución de Rusafa y recibió por ello 27 s. (Idem, f. 12v.) Macià de Conques hizo lo mismo en Meliana por $25 \mathrm{~s}$.

(22) Las parroquias son 12.

(23) C.C.M.A., J-2, f. 4v., 5, El sistema de alarma funcionó de forma continua desde agosto hasta mayo, al principio las señales se hacían durante el día y la noche. La llegada del invierno obligó a la construcción de un cobijo en el cimborrio de la catedral para albergar a los encargados de transmitir las señales (Idem, f. 5v.) A partir de noviembre se suspenden las señales por la noche y el salario de los que las transmiten y el salario de lso que las transmiten queda establecido en 3s. (Idem, f. 12v.). En 1357 se recibe el sueldo regularmente cada més. (Idem, f. 16v., 19, 21).

(24) Idem, f. $2 v, 3,4 v,, 5$ (bis), 5 (bis) v., 12 v., 13 v., 18 v., 20, 30 v., recoge algunos gastos de la ciudad en obtener información que abarcan de agosto del 56 a mayo del 57 . Otras fuentes de información son los cónsules comerciales, (Idem, f, 4).

(25) M.C., A-13, mano 1, f. 13v-15. Recoge todas las medidas tomadas.

(26) Idem, 19v., 20. Se elige a: Berenguer d'Abella, Galceran de Thous, Francesc de Vilarasa, Guillem Abelló, Miquel de Palomar, Francesc Marrades, Pere Malet, Pere Fuser, Arnau de Valleriola, Berenguer de Tapioles, además del Consejo real y Blasco Ferrandez de Heredia y Guillem Mir. 
da enviar mensajeros al rey, que se encontraba en Perpiñán, solicitando su presencia.

Los delegados por el Consejo emprenden rápidamente su misión ordenando que se hiciesen fosos alrededor de los arrabales y otras defensas (27), peros estos proyectos requieren dinero (28) por lo que recurren al pleno. El 18 de ese mismo mes, son autorizados a solicitar préstamos para hacer frente a estos y otros gastos concernientes a la guerra.

Todo lo relacionado con el conflicto bélico será, pues, resuelto por el Consejo a través de dos comisiones, una más reducida que se hará cargo de solucionar los problemas de la ciudad con respecto a estas cuestiones y otra más amplia que asumirá los referentes al reino (29).

El monarca, ante los mensajes que llegan de las ciudades (30) y de sus oficiales, aunque todavía no ha recibido el ultimátum - 4 septiembre de 1356 -, da órdenes orientadas principalmente a la defensa.

El 30 de agosto escribe al infante Ramón Berenguer, comunicándole que, percibidas sus noticias sobre las maniobras castellanas, ya le ha remitido instrucciones al efecto. Al mismo tiempo le pone al frente de estos asuntos;

«E par que, pus aquí nós no som, de neguna altra persona los afers no puguen o dejen haver mellor endreçament que de vós; per qué.us pregam que en açò mostretes gran diligéncia e cura« (31).

Le participa también lo que ha previsto con respecto a las compañias que le ha pedido, dejando claro:

«Car tot hom deu ésser e estar apperellat per defendre la terra e el regne on és poblat» (32); deniega con ello la soldada pedida por los naturales.

(27) Se ocupan además de otros aspectos, ordenan tambiên hacer tahonas dentro de la ciudad para asegurarse la harina. Se recogen diversos gastos por este concepto en C.C.M.A., J-2, F. 4, 5, 11, 11v., 12 y 13 .

(28) Los pagos por este concepto comienzan en agosto del 56, C.C.M.A., J-2, f. 4, 4v., y 7.

(29) Ver notas 19 y 26.

(30) La correspondencia entre el rey y la ciudad no se conserva. En C.C.M.A., J-2, f. 4, $4 v$, y 5 (bis), se recoge los gastos de una embajada que la ciudad envió al rey hasta Perpi. ñan.

(31) Gubern, R., Op. Cit., p. 123.

(32) Idem, 124. 
En cuanto a su presencia en València, le informa que no puede venir si no lo hace bien pertrechado; en otras condiciones es trabajo perdido:

«Car regne de Valéncia no és terra de la qual nós poderosament pugam offendre Castella, car les comarques e les fronteres són en tal disposició que no.s poria fer; e solament per deffendre, e no per offendre, no seria bé que nós estiguéssem en lo regne de València» (33).

Las gestiones diplomáticas que está intentando con Francia, patria de la esposa de Pedro I, y con Enrique de Trastámara, que requieren su presencia en Perpiñán, se explican veladamente en pocas palabras:

«E pensats que nós no estam açí per deli tament ni ab les mans plegades» (34).

Le pone también al corriente de la ruptura de negociaciones con su hermanastro Fernando; la noticia no es meramente informativa. La importancia de las posesiones de este infante en la Corona de Aragón no escapa al rey. Siendo todavía heredero al trono y con ocasión de su donación ya había señalado:

«Los dits llocs, qui són claus de tots nostres reialmes» (35).

Pedro IV, atendiendo a la defensa de los pasos entre los dos reinos manda:

"Que se pusiese gran vigilancia en fortificar la ciudad de Valencia...; y proveyóse que ciertas compañías de gente de caballo estuviesen en el castillo de Jumilla y en Biar para correr aquella frontera de los enemigos, y que don Pedro Maza de Lizana estuviese en Mojén y en la Fuente de la Higuera, y otras compañías de caballo estuviesen en Chiva y Siete Aguas" (36).

Las cartas del rey comienzan a llegar al Consejo a partir del 31 de agosto. Ese día se recibe la credencial de Pere Guillem Català y Pere Boill, encargados de explicarles todo lo dispuesto sobre la custo-

(33) Idem, 125. ZURITA. J., Op. Cit., p. 300-301.

(34) Ibidem. Hasta el 8 de noviembre de 1357 no se firmará el tratado de Pina con Enrique de Tratamara.

(35) Crònica de Pere el Cerimoniós (Crònica). Ed. preparada por SOLDEVILA. F. Les quatre grans Cróniques. Barcelona 1971. p. 1019.

(36) ZURITA, J., Op. Cit, p. 301. 
dia y defensa del reino (37). Asimismo, el nombramiento de Pedro, señor de Xèrica, como capitán al norte del Júcar (38). No se registra, sin embargo, el nombramiento de Alfonso, conde de Dénia, como capitán al sur del mismo río, y que según Zurita se hace en la misma fecha. Hay que señalar que, en contra de lo que es habitual en ese tipo de registros, ese día se aprecian huecos y no hay notas sobre lo tratado en la sesión.

Medidas similares serán tomadas en el caso de Aragón (39). No hay que olvidar que ambos reinos hacen frontera con Castilla y, como señala Gutiérrez de Velasco, la lucha en un principio se advierte en forma de tanteos en la zona de contacto, para localizar seguramente el punto débil del enemigo (40).

Pedro IV no sólo adopta medidas de carácter general, sino que, aprovechando las circunstancias, trata de mejorar su patrimonio. El 7 de septiembre el Consejo acepta, después de especificar que no tiene obligación, la orden del rey transmitida por el mestre racional:

"Que com faran los vallejaments de la dita ciutat, feessen vallejar lo Reyal del dit senyor rey, lo qual ha en València» (41).

\section{CONSECUENCIAS DEL ULTIMATUM}

Sólo en dos sesiones del Consejo se toman decisiones relacionadas con la guerra en el mes de intervalo que media entre el el ultimátum del Castellano y la declaración de guerra del Ceremonioso - 4 de octubre - . Entretanto, y a pesar de que la actividad del Aragonés se multiplica, parece que sus correos se dirigen principalmente a Aragón (42). Ninguna misiva real ha quedado registrada en las actas del Consejo en esas fechas. Los acuerdos, por su parte, son de distinta indole y no reflejan la gravedad de la situación por la que atreviesa el reino.

(37) M.C., A-13, mano 1, f. 23 (Perpiñan, 19 de agosto).

(38) Idem, f. 23 v. (Perpiñan, 19 de agosto).

(39) GUTIERREZ DE VELASCO, A. Ha estudiado diversos aspectos de esta guerra desde las perspectiva aragonesa.

(40) IDEM, La conquista de Tarazona en la guerra de los dos Pedros (año 1357). Jerónimo Zurita. Cuadernos de Historia, 10 - 11. (1960) p. 72.

(41) M.C., A-13. mano l. f. 25-25v. (Perpiñan, 24 de agosto).

(42) GUTIERREZ DE VELASCO, A., Op. Cit., ver notas de la p. 75. 
El primero, sólo adquiere su verdadero significado colocado en el lugar que le corresponde; de otro modo, es un dato más que no ayuda a comprender la situación.

Pedro I, aprovechando la oferta de Alacant y Orihuela que le hicieron los infantes aragoneses que militaban en su bando, decide empezar su campaña por esta zona. El 8 de septiembre ha tomado Alacant, mientras las tropas valencianas, bajo el mando del gobernador y Gilabert de Centelles, hostigaban Requena y Utiel. Puestos estos hechos en conocimiento de Pedro IV, envía instrucciones a miembros de su Consejo (43). Les recomienda que, en lugar de asediar Alacant, fortifiquen los pasos hacia València y otras medidas Pedro I, enterado a 16 de septiembre de que: «Los capitanes del rey de Aragón habían hecho grande daño por sus fronteras y habian quemado el arrabal de Requena y muchos lugares de aquella comarca" (44), organiza sus tropas en tres frentes dando órdenes de que:

«El infante [Dn Fernando] hiciese guerra por la parte de Játiva con dos mil de caballo, y el infante don Juan y don Tello señor de Vizcaya..., con mil y quinientos entrasen en Aragón por las partes de Soria; y el rey con la otra gente - que se decía ser hasta cuatro mil de caballo - se habían de juntar en Villarreal para evenirse a Cuenca y Requena y de allí hacer su entrada en el reino de Valencia» (45).

Así pues, mientras Pedro IV enviaba tropas para hacerle frente, el castellano desplazaba su acción personal más hacia el norte. Pero según el despliege establecido por Pedro I ninguna frontera quedaría desguarnecida. Mientras él se dirige hacia Requena, el infante Fernando, tras renunciar a la fidelidad que le debe al aragonés - 17 septiembre - marcha hacia Biar intentando suscitar los resquemores de la pasada Unión. Los de Biar, según Zurita, se muestran contrarios a sus planes, pero la actividad de Fernando y las tropas castellanas en esta frontera, obligó a los consejeros reales, a cuyo frente se encontraban el infante Ramón Berenguer y el go-

(43) GUBERN, R., Op. Cit, p. 129-134. Carta dirigidas al mestre racional y Arnau Joan, consejeros del rey. (Perpiñán, 17 septiembre).

(44) ZURITA, J., Op. Cit, p. 309.

(45) Idem, pg. 309-310. 
bernador, a presentarse en el Consejo y municipal del 1 de octubre para pedir ayuda; se mandó a los jurados:

"Que deguesen fer exir los hòmens a cavall de la dita ciutat ensemps ab certa companya de hòmens de peu per anar vies les parts de Biar per defendre, contrastar e suayir los enamichs, sotsmeses del rey de Castella, qui eren segons que.s deya, en Vilena o en aquelles parts per fer entrada dins lo regne de València per dampneyar les terres e sotsmeses del dit senyor» (46).

El Pleno acordó por respeto al rey y por el bien público acceder, aunque con algunas condiciones:

- El ordenamiento tendrá una validez temporal y podrá ser revocada por el Consejo.

- Las huestes deberán cobrar antes de su partida y no estarán obligadas a permanecer más tiempo si la soldada no se les atribuye con tres días de antelación.

- El lugarteniente del mestre nacional deberá extender carta acreditativa de que todo ello no será tomado como antecedente para poceder contra sus fueros y privilegios.

El otro acuerdo, estará orientado a resolver el problema financiero producido en la ciudad por las necesidades de la guerra.

El 3 de octubre el órgano municipal:

«Vehent que de necessitat e per gran profit e utilitat de la dita ciutat, los dits valls, portals, verdesques e altres fortituts de aquells, en tot cas, devien ésser fets o duyts a acabament. Vehent que, per deffensió de la dita ciutat e offensió dels enemichs, era necessari que la dita ciutat fes e tengués compliment de passadors e altres arneses" (47); designa a una comisión (48) a la que autoriza, junto a los jurados y al subsíndico Joan Sot, a absolver a Guillem Abelló de algunos pagos que debe hacer en nombre de la ciudad, y a negociar ese dinero a fin de obtener los máximos intereses (49). Guillem Abelló, encargado del cobro de los impuestos y del pago de ciertas

(46) M.C., A-13, mano 1, f. 28-28v.

(47) Idem. f. 30. Las armas utilizadas según algunos albaranes de gastos son: saetas, dalles y ballestas (C.C.M.A., J-2, f. 9v., 13, 14). A partir de 1357 hay noticias de que se importan de Mallorca.

(48) La comisión está formada por; Pere Maschó, Pere Eymerich, Jaume Donat, Miquel Lorenç, Arnau Valleriola y Pere Castellà.

(49) M.C., A-13, mano 1, f. 30-30v. 
cantidades con cargo a esos ingresos, es definitivamente relevado de su misión cuatro días más tarde. La comisión quedará encargada de la inversión de ese dinero donde produzca mayores ingresos (50).

\section{DECLARACION DE GUERRA}

Pedro IV, solucionados los asuntos que le retenían en Perpiñán, se dirige a Barcelona. Una vez allí, tras contestar a la embajada del Castellano, decide comunicar a todos su reinos la declaración de guerra, 4 de octubre. Aunque según la crónica se notificó a todos sus reinos, y entre ellos:

«A tots los nobles, barons, cavallers e generoses del regne de $\mathrm{Va}$ lència. E encara fon notificat a totes les ciutats, viles e llocs reials del dit regne de València (51).

Ni esa carta, ni la solicitud de recursos que se hizo al Consejo pocos días después (52) han quedado registradas en sus actas.

El Ceremonioso de Barcelona pasará a Lérida a reunir las huestes que deberán acompañarlo el encuentro del Castellano:

«E d'allí tendríem nostre camí ab nostre poder vers aquelles parts on sabéssem ésser lo dit rei de Castella» (53).

Con este propósito se dirige primero a Zaragoza, después a Calatayud para organizar la guerra. Estando en este punto y a mediados de noviembre recibe una embajada de Pedro I fechada un mes antes en Sevilla (54).

El reino de Valencia, entre tanto, y atendiendo a la petición real, se ocupa de su propia defensa.

Los infantes Pedro y Ramón Berenguer se encuentran en la frontera sur, desde donde solicitan ayuda al gobernador para introducirse en Castilla. Este, que se encontraba al frente de sus tropas y de 500 hombres que le concedió la ciudad (55), traslada su petición al Consejo. En la sesiôn del 10 de octubre, el pleno, tras considerar

(50) Los primeros pagos que se anulan son: 5.600 libras destinadas a la redención de cen sales, y las 1.800 que debían entregarse a Arnau de Valleriola para recuperar las carnicerías de la ciudad. Ambos pagos debían hacerse efectivos en febrero de 1357.

(51) Crönica, p. 1128.

(52) GUTIERREZ DE VELASCO, A. La financiación aragonesa de la "guerra de los dos Pedros». Hispania, 19 (1959). Nota 3 de la p. 6.

(53) Crónica, p. 1129.

(54) Ibidem. 
que los cuarenta marinos que quedan en la ciudad son necesarios para la defensa de sus costas, y la exención que les conceden sus privilegios:

«Atenent, encara, que la dita ciutat no era tenguda trametre los dits hòmens de mar, posat que fossen en la dita ciutat, ço que no eren, segons privilegis e bones costums de la dita ciutat, com los enemichs no fossen dins lo regne de València» (56) acuerda que puedan ser reclutados los marinos encontrados en la ciudad. Esta decisión, por falta de efectivos, no debió alcanzar los resultados apetecidos. El 23 del mismo mes son los propios infantes desde Ontinyent (57) los que recurren al Consejo con la misma petición (300 o al menos 200 marineros). Nuevamente la corporación pone de manifiesto su buena voluntad accediendo, aunque señala al mismo tiempo que no se dispone de esos efectivos. Los marineros de la ciudad estaban con el gobernador o dedicados al corso.

Pedro I, al que a mediados de octubre habíamos localizado en Sevilla, tras reorganizar sus tropas debe ponerse nuevamente en marcha hacia las fronteras de la Corona de Aragón. El Aragonés, que a través de sus espías sigue sus pasos teme, en principio, un ataque al reino de València; por ello a 18 de octubre escribe a la corporación municipal comunicándoles que los caballeros y jinetes que van a salir para acudir en su defensa ya están preparados y son en total alrededor de 250:

"Los quals entre tots poden ésse CCL o pus, e açò, així com dit és, fem per deffensió de la ciutat e regne de València» (58).

Asimismo, Pedro IV, que está interesado en el enfrentamiento personal, para lo que está dispuesto a trasladarse a Valencia, tiene sus dudas sobre el punto donde aquel centrará su ataque; por ello dispone, asimismo, lo que debe hacerse en el caso de que el Castellano se dirija a Aragón. Sus órdene son que el infante Ramón Berenguer, junto con las tropas remitidas a València, se traslade a la

(55) M.C., A-13, f. 33v. Los 500 jinetes cuestan a la ciudad $20.000 \mathrm{~s}$.

(56) Esta protesta se presenta sistemáticamente, tanto cuando se accede a la petición como cuando se deniega.

(57) M.C., A-13, mano 1, f. 35. La carta está fechada el 22 de octubre.

(58) Idem, f. 36. La ciudad también sigue los pasos del castellano, a 13 de octubre se paga el mensajero que comunicó que 1000 jinetes debían partir de Granada en ayuda de Pedro I (C.C.M.A., J-2, f. 6v). 
frontera aragonesa, y pide a la ciudad que, en ese caso, le envíe mil hombres entre los que deben encontrarse doscientos buenos ballesteros (59).

El 23 del mismo mes vuelve a dirigirse al Consejo (60); tal como temía, las noticias parece que confirman la marcha de Pedro I sobrella frontera aragonesa; por ello pide que se cumplan las órdenes establecidas. El infante Pedro quedará al frente de las compáñ̃ías que permanecerán en València.

Ambas cartas son recibidas por el Consejo valenciano el 10 de noviembre y, a tenor de la respuesta dada por éste, la marcha del ejercito castellano hacia Aragón no parece tan clara:

«En lo dit cas, que.l rey de Castella entre en lo regne d'Aragó o tenga girada la cara a aquell, e la vostra altea, senyor, se haja afrontar al dit rey, la dita ciutat vostra de València, esguardada la gran naturalea e amor que a ha vós, senyor, e a la vostra alta corona, jasia sia molt oppressa, s'és offerta e s'offer apparellada trametre a la vostra real magestat los dits. $M$. hòmens» (6l).

Este año, no sólo no se mandarán los mil hombres hacia Aragón, sino que tambiên se negarán a 24 de noviembre los quinientos hombres que solicita el infante Pedro. El Consejo centra su atención en la ciudad.

«Per ço com la dita ciutat estaba ab reguart d'enemichs» (62).

La inquietud continúa y a finales de año se teme un ataque a València. El 11 de diciembre el gobernador comunica al Consejo que se están haciendo grandes preparativos por parte del enemigo en la frontera, mandando que en caso de que se adviertan maniobras de penetración se ponga en marcha la planificación hecha por los diputados de la guerra.

En la misma reunión se exponen las medidas acordadas; el Consejo se muestra conforme, dando su aprobación y encomendando su perfeccionamiento a sus artífices y al gobernador.

Esta ordenación estaba dirigida, por su estrategia, al frente medio - el más próximo a València -. Las disposiciones aprobadas se

(59) M.C., A-13, mano 1, f. 36v.

(60) Ibidem.

(61) Idem, f. 37. Envían carta al rey con esa misma fecha.

(62) Idem, f. 37v. 
refieren al reclutamiento y organización de la tropa (63).

$1^{\circ}$ Que se haga bando comunicado bajo "pena de cos e d'haver e de feeltat que són tenguts al senyor rey", que todo infante o jinete al son de la campana de la catedral se prepare a seguir la bandera.

$2^{\circ}$ Una vez salida la bandera de la ciudad, algunos hombres recorrerán la huerta y sus alrededores, obligando a todos a seguirla.

$3^{\circ}$ El gobernador comunicará a Morvedre, por toda la plana de Borriana y por la Vall d'Uixó, que todos, bajo la pena ya dicha, deben presentarse para seguir la bandera.

$4^{\circ} \mathrm{Si}$ los enemigos quieren entrar por Llíria, se reunirán todos en Paterna; si se introducen por Xiva o la Hoya de Bunyol, la concentración de la tropa se hará en Quart.

$5^{\circ}$ Una vez todos reunidos el ejército se organizará en dos cuerpos: las tropas de la ciudad y las del reino. A su vez, se subdividen en caballería e infantería.

Las tropas de la ciudad encabezarán la marcha; la caballería irá precedida por: el gobernador, que llevará la bandera de San Jorge, Berenguer d’Abella, Blasco Ferrández, Ramón Castellà, Pere Boÿl, Francesc de Vilarasa, Galceran de Thous y Joan Pertusa. La ciudad portará la bandera real: después la infantería, y a su frente: Perez Roiz de Corella, lugarteniente del justicia criminal, Pere Calderó, Arnau Scrivà, Jacme Claramunt, Berenguer Dalmau, Pere Malet, y los jurados, Nicolau de Valleriola y Roy Martínez de Sent Adrià.

Las restantes tropas, formadas por las compañías y huestes de Sagunt, Vila-real, Vall d'Uixó, Borriana y Castelló estarán a cargo del infante Ramón Berenguer y de Pedro, señor de Xèrica. La caballería tendrá al frente a Berenguer Castellnou, Gilabert de Cruÿlles, Guillem de Vilaragut, Pere Sent Climent y los que nombrase el señor de Xèrica de entre los suyos; encabezando la infantería debían ir los justicias de cada lugar y los nombrados por el mismo noble, parte de sus tropas deben formar, además, a la derecha un ala que será capitaneada por Miguel Pérez Zapata.

Si antes de que se puedan reunir todas las huestes de la villas es necesario dar la batalla, la infantería de la ciudad se dividirá entre los dos cuerpos.

(63) Idem, f. 39.40. 
Cada compañía estará formada por cincuenta hombres, que deben seguir su estandarte bajo la pena establecida (64).

Todo el que disponga de mula o mulo estará obligado a aparejarlo con perpunte o sobreseñal y salị con él como si de caballo se tratara.

La infantería de la ciudad, agrupada en decenas, deberá contar entre sus componentes con dos ballesteros.

A través del diario del Consejo, no nos ha sido posible aclarar si lo planificado se puso en marcha y cuándo. Sabemos, sin embargo, que los mil hombres prometidos al rey no saldrán hasta 1357, cuando ya el Castellano ha establecido su campamento en Molina, y tras algunas negociaciones.

A partir de esa fecha, los acuerdos que toma la Corporación municipal se dirigen, principalmente, a resolver algunos de los problemas que la guerra plantea a sus conciudadanos.

El 16 de diciembre, y a súplica de amigos y parientes, deciden enviar una persona a recabar información y tratar el rescate de los tripulantes desaparecidos en una de las dos galeras que se hubieron de enfrentar a Bocanegra, capitán genovés, cuando iban a avituallar Alacant.

Acceden incluso a colaborar a su liberación con dinero (65).

Días más tarde tendrán que resolver la reclamación contra los impuestos, que presentan los ciudadanos obligados a comprar monturas en defensa de la ciudad. El Consejo acuerda que el municipio se haga cargo del impuesto de la primera compra (66).

Se ocupan además de regularizar algunos artículos afectados por la guerra y otros necesarios para hacerle frente, marcan el precio de las carnes, ante la dificultad de traerlas de Castilla (67), y más tarde favorecerán la entrada de trigo subvencionándolo con una prima (68).

(64) C.C.M.A., J.2, f. 9v, y 17. El gasto de los estandartes corre también a cargo de la ciudad.

(65) M.C., A-13, mano 1, f. 4lv. 42. La ciudad envía dos mensajeros que cobraron $100 \mathrm{~s}$. cada uno (C.C.M.A., J-2, f. 13 y 18 .

(66) M.C., A-13, mano 1, f. 58 (20 enero de 1357).

(67) Idem, f. $58 \mathrm{v}$. (20 de enero de 1357).

(68) Idem, mano 3, f, 6,6v. a 3 de junio de 1357 se ofrece una prima de $2 \mathrm{~s}$. por cahis al que traiga trigo de fuera de Valencia a su almudín. A mediados de enero de 1356 se halia hecho igual pregón. 
La última decisión de ese año fue consentir en la venta del castillo de Guadalest al infante Pedro, aunque imponen ciertas cláusulas que permitan su recuperación, ya que por privilegio esa villa no puede ser separada de la Corona (69).

Como ya hemos visto, hasta diciembre de ese año se intercambian mensajes entre ambos reyes (70), pero éstos no conducirán por el momento a ninguna solución. La primera tregua no se conseguirá hasta mayo de 1357 y se deberá a las gestiones de un legado papal.

El tipo de fuentes manejadas no permite un estudio global y pormenorizado de la guerra. Sólo es posible seguirla cuando su incidencia repercute, por alguna cosa, en la ciudad y por ende en su Consejo como órgano representativo de la misma. En su actuación, a través de todo lo expuesto, se distingue una doble finalidad, la custodia de la ciudad y del Reino, tanto a nivel táctico - defensa y organización de tropas - , como desde el punto de vista jurídico, ya que trata de salvaguardar en todas las ocasiones los fueros y privilegios.

(69) Idem, mano I. f. 45 (25 diciembre 1356).

(70) Crónica, p. 1129-1130 